\title{
A Comparative Study of Landsat TM and SPOT HRG Images for Vegetation Classification in the Brazilian Amazon
}

\author{
Dengsheng Lu, \\ School of Forestry and Wildlife Services, Auburn University, 602 Duncan Drive, Auburn, AL 36849 \\ (luds@auburn.edu)
}

Mateus Batistella,

Brazilian Agricultural Research Corporation, Embrapa Satellite Monitoring, Campinas, São Paulo, Brazil

Evaristo E. de Miranda, and

Brazilian Agricultural Research Corporation, Embrapa Satellite Monitoring, Campinas, São Paulo, Brazil

\section{Emilio Moran}

Center for the Study of Institutions, Population, and Environmental Change (CIPEC), Indiana University, Bloomington, IN, and the Anthropological Center for Training and Research on Global Environmental Change (ACT), Indiana University, Bloomington, IN

\section{Abstract}

Complex forest structure and abundant tree species in the moist tropical regions often cause difficulties in classifying vegetation classes with remotely sensed data. This paper explores improvement in vegetation classification accuracies through a comparative study of different image combinations based on the integration of Landsat Thematic Mapper (TM) and SPOT High Resolution Geometric (HRG) instrument data, as well as the combination of spectral signatures and textures. A maximum likelihood classifier was used to classify the different image combinations into thematic maps. This research indicated that data fusion based on HRG multispectral and panchromatic data slightly improved vegetation classification accuracies: a 3.1 to 4.6 percent increase in the kappa coefficient compared with the classification results based on original HRG or TM multispectral images. A combination of HRG spectral signatures and two textural images improved the kappa coefficient by 6.3 percent compared with pure HRG multispectral images. The textural images based on entropy or second-moment texture measures with a window size of 9 pixels $\times 9$ pixels played an important role in improving vegetation classification accuracy. Overall, optical remote-sensing data are still insufficient for accurate vegetation classifications in the Amazon basin.

\section{Introduction}

The moist tropical forests in the Amazon have special importance in the biodiversity and climate of the world. High deforestation rates in the Amazon have been associated with the expansion of highways and roads and the growth of Amazonian cattle ranching and soybean farming (Skole et al., 1994; Laurance et al., 2004). Large areas of primary forests have been converted into a mosaic of agricultural lands, pastures, and different successional formations (Lucas et al., 2000; Roberts et al., 2002). The unprecedented tropical deforestation rates have been regarded as an important factor in the climate change and environmental degradation at regional and global scales (Skole et al., 1994). In order to better understand the consequences caused by deforestation and landscape transformations in the region, an international research program called Large Scale Biosphere-Atmosphere Experiment in Amazonia (LBA), has been carried out since 1997 (http://lba.cptec.inpe.br/lba/). Through this program, an important 
research topic is the mapping and monitoring of land-use/land-cover changes. A research team from the USA (Indiana University and Indiana State University) and Brazil (Embrapa: Brazilian Company of Farming Research and INPE: National Institute of Space Research) has made great efforts to improve the accuracy of vegetation classifications, especially successional vegetation classification (Mausel et al., 1993; Moran et al., 1994; Brondízio et al., 1996; Lu, 2005a).

In the moist tropical regions, complex forest stand structure and abundant tree species often cause difficulties in classifying vegetation classes using remotely sensed data. Most previous research in the moist tropical regions provided only coarse vegetation classes, such as primary forest and successional vegetation (Adams et al., 1995; Roberts et al., 2002). However, the biomass densities of different successional stages vary considerably, ranging from less than 2 $\mathrm{kg} / \mathrm{m}^{2}$ in initial successional vegetation to greater than $20 \mathrm{~kg} / \mathrm{m}^{2}$ in advanced successional vegetation $(\mathrm{Lu}, 2005 \mathrm{~b})$. The biomass densities of primary forests also vary considerably, ranging from approximately $12 \mathrm{~kg} / \mathrm{m}^{2}$ to greater than $50 \mathrm{~kg} / \mathrm{m}^{2}$ due to different environments. Obviously, a single class of primary forest or successional vegetation is not suitable for many applications such as carbon estimation or land degradation assessments. Lu (2005a) has provided a detailed summary of the previous efforts on vegetation classification using field measurements and satellite images. A new approach based on the complexity of forest stand structure was then developed for successional vegetation classification. But in practice, the collection of a large number of field measurements, including vegetation stand attributes (e.g., height, diameter at breast height), is often very challenging, especially in the Brazilian Amazon due to the difficult access to some remote areas and the intensive labor required in an environment characterized by such high biodiversity. Thus, it is important to find a suitable approach for improving vegetation classification performance based on the use of remotesensing features, such as spectral, spatial, and temporal characteristics to address these needs. Without accurate land-cover classification, estimates of biomass and carbon are fraught with degrees of error that make modeling subject to unacceptable uncertainties.

Time series of Landsat Thematic Mapper (TM) data have been extensively used for land-cover or vegetation classification in the moist tropical regions (Mausel et al., 1993; Moran et al., 1994; Adams et al., 1995; Foody et al., 1996; Brondízio et al., 1996; Roberts et al., 2002; Vieira et al., 2003; Lu et al., 2004), but a fine vegetation classification based on the medium spatial resolution images have proven difficult. Although higher spatial resolution data, such as SPOT High Resolution Visible (HRV), and recently SPOT High Resolution Geometric (HRG) instrument data are readily available, they are frequently used for urban-related studies (Marceau et al., 1990; Gong et al., 1992; Shaban and Dikshit, 2002), and their roles for improving vegetation classification, especially in the moist tropical regions have not been examined in detail. Increased spatial resolution considerably reduces the mixed pixel problem, and effective use of spatial information may improve detailed vegetation classification accuracies. Two image processing techniques for making use of the higher spatial resolution information are often used for improving land-cover classification performance. One approach is based on data fusion through the integration of multispectral and high spatial resolution information. Previous research has explored the data fusion approaches for improvement of land-cover or vegetation classification (Welch and Ehlers, 1987; Yocky, 1996; Haack et al., 2002). The second approach is to use the spatial information inherent in high spatial resolution imagery. In particular, textures have proven useful in improving land-cover classification accuracy (Marceau et al., 1990; Shaban and Dikshit, 2001; Chen et al., 2004). Many texture measures have been developed since the 1970s (Haralick et al., 1973; Kashyap et al., 1982). Of the many texture measures, the grey-level co-occurrence matrix (GLCM) texture measure is frequently used. 
In the moist tropical regions, the classification of detailed vegetation classes with remotely sensed data is still very difficult and the use of higher spatial resolution images in improving vegetation classification accuracy is poorly understood. Hence, this paper aims to explore the possibility of mapping fine vegetation classes through a comparative analysis of different image combinations, such as the incorporation of the spectral features in the Landsat TM image and the spatial features in the SPOT HRG image, as well as the combinations of textures and spectral signatures. A maximum likelihood classifier was used to classify different image combinations into thematic maps, followed by an accuracy assessment using reference data to evaluate the classification performance and to identify suitable image processing procedures for vegetation classification in the study area.

\section{Study Area}

The study area is located at Machadinho d'Oeste in northeastern Rondônia (Figure 1). A welldefined dry season lasts from June to August. The annual average precipitation is 2,016 mm and annual average temperature is $25.5^{\circ} \mathrm{C}$ (Rondônia, 1998). The terrain is undulating, ranging from 100 to $450 \mathrm{~m}$ above sea level. Several soil types, mainly alfisols, oxisols, ultisols, and alluvial soils, have been identified (Bognola and Soares, 1999). Although Machadinho d'Oeste has a specific institutional and architectural design (Batistella et al., 2003), the study area is representative of rural settlements in the Amazon and mimics the dynamics of deforestation and land-use cycles found in other parts of the region, specifically in the state of Rondônia.

The settlement of Machadinho d'Oeste covers about 2,000 $\mathrm{km}^{2}$ and is adjacent to the borders with the states of Amazonas and Mato Grosso. The major deforestation began in late-1980s. Due to land-use intensification, most successional vegetations are in the initial and intermediate stages, and limited areas are in the advanced stage. The majority of successional vegetation has biomass density of less than $15 \mathrm{~kg} / \mathrm{m}^{2}$, but most of the primary forest has biomass density greater than $20 \mathrm{~kg} / \mathrm{m}^{2}$ (Lu, 2005a). In deforested areas, pastures, perennial crops (e.g., coffee, cocoa), agroforestry (e.g., cocoa associated with the rubber tree), and small fields of annual crops are the most common land-uses. Because of the high temperature and precipitation, the soil nutrients are lost rapidly and soil erosion can be severe, thus the land degrades rapidly if not properly used, resulting in the land being left to fallow, setting the stage for the return of successional vegetation. Settlers, rubber tappers, and loggers inhabit the area, transforming the landscape through their economic activities and use of resources (Batistella, 2001). Farming systems are mainly household-based, and little depends on larger group efforts. Rubber tappers have rights over communal forest reserves where they practice extraction. Loggers play a major role in providing access to remote areas within the settlement as they open trails through the forest to reach valuable species.

\section{Methods}

Before implementing field data collection and image classification, a suitable vegetation classification system was required. The selection of a vegetation classification scheme was motivated by two factors: our previous experience in vegetation classification since the mid-1990s (e.g., Mausel et al., 1993; Brondízio et al., 1996; Lu et al., 2004) and the requirement of detailed vegetation information for our Amazonian research (Batistella and Moran, 2005). Table 1 summarizes the major characteristics of the vegetation classification system used in this study. Pastures were separated from other vegetation classes based on the percentage of grass cover and the limited presence of seedlings and saplings. Successional vegetations were assigned solely to the vegetation areas where grass cover was less than 25 percent, which generally occurred in sites that had been abandoned for more than two years. The separation of different successional stages was based on stand structural parameters: biomass and averages of forest stand diameter and height. The primary forest was separated into upland dense forest, 
upland open forest, and flooding forest based on biomass density, moist conditions, and topographic factors. The coffee and cocoa plantations and the association of these species with other economic or successional species were grouped as an agroforestry/perennial agriculture class.

\section{Field Data Collection}

Our first fieldwork in this study area was conducted during the dry season of 1999. Preliminary image classification, based on a 1998 TM image and band composite printouts, indicated candidate areas to be surveyed, and a flight over the areas provided visual insights about the size, condition, and accessibility of each site (Batistella, 2001). The surveys were carried out in areas with relatively homogeneous ecological conditions (e.g., topography, distance from water, and land-use) and uniform physiognomic characteristics. After defining the area to be surveyed (plot sample), three nested subplots $\left(1 \mathrm{~m}^{2}, 9 \mathrm{~m}^{2}\right.$, and $\left.100 \mathrm{~m}^{2}\right)$ were randomly selected to accurately represent the variability within the plot sample (Figure 2). A detailed description of field data collection methods is found in Batistella's dissertation (2001). During fieldwork, stand parameters, such as total tree height and diameter at breast height, in 26 sample plots covering different stages of successional vegetation and 14 sample plots covering primary forests were measured in this study area. These measurements were analyzed for separation of different successional stages and primary forest classes with the Canonical discriminant analysis (Lu et al., 2003a).

The majority of fieldwork was conducted in August 2002 and August 2003. During fieldwork in August 2002, an Ikonos color composite (acquired on 28 May 2001) was used to assist field data collection for different successional stages, agroforestry/perennial agriculture, and degraded and cultivated pastures. In August 2003, a SPOT HRG color composite was used to assist collection of more ground data. Every sample plot was registered with a global positioning system (GPS) device to allow further integration with spatial data in both geographic information systems (GIS) and image processing systems. Some primary forest sample plots were identified with visual interpretation of Ikonos or HRG color composite based on our field experiences. The collected sample plots were then separated into two groups: one group to be used for training samples in the maximum likelihood classification, and another group to be used for assessing classification results.

\section{Image Data Collection and Preprocessing}

Two sensor data, Landsat-5 TM and SPOT5 HRG, were used in this research. The TM image with 30-meter spatial resolution has six bands, covering three visible bands (blue, green, and red), one near-infrared (NIR) band, and two shortwave-infrared (SWIR) bands. The HRG image has five bands, covering one panchromatic band with 5-meter spatial resolution, two visible (green and red) bands, one NIR band with 10-meter spatial resolution, and one SWIR band with 20-meter spatial resolution. The TM image was acquired on 08 July 2003 with sun elevation angle of $42.966^{\circ}$ and sun azimuth angle of $45.719^{\circ}$. The HRG image was acquired on 26 June 2003 with sun elevation angle of $51.065^{\circ}$ and sun azimuth angle of $31.848^{\circ}$. Both sensor data were acquired during the dry season with similar climate conditions. Ikonos data (4-meter spatial resolution), acquired on 28 May 2001, were employed during the fieldwork to assist the collection of sample plots for different vegetation classes.

Accurate image registration and atmospheric correction are two important aspects in an image preprocessing procedure. Image-to-image registration between TM and HRG images was conducted, using the HRG image as a reference image, so that both TM and HRG images have the Universal Transverse Mercator coordinate system. A nearest-neighbor algorithm was used to resample the TM images to 30-meter spatial resolution. A registration error of 0.1816 pixels ( $x$ error: $0.1409, y$ error: 0.1145 ) for the TM image was obtained during image registration. 
Many approaches, ranging from simple relative calibration and dark-object subtraction to complex model-based calibration approaches (e.g., the $6 \mathrm{~S}$ radiative transfer code for atmospheric correction), have been developed for radiometric and atmospheric normalization or correction (Chavez, 1996; Vermote et al., 1997; Tokola et al., 1999; Song et al., 2001; Canty et al., 2004). Because the dark-object subtraction approach was strictly an image-based procedure, and corrected for the effects caused by sun zenith angle, solar radiance, and atmospheric scattering (Chavez, 1996; Lu et al., 2002), this approach was used in this study for atmospheric correction of TM and HRG images, based on the following equations:

$$
R_{\lambda}=\mathrm{PI} * \mathrm{D} *\left(L_{\lambda}-L_{\lambda . \text { haze }}\right) /\left(\operatorname{Esun}_{\lambda} * \operatorname{COS}(\theta)\right),
$$

where $L_{\lambda}=\mathrm{DN}_{\lambda} / A_{\lambda}$, for SPOT HRG data, and

$$
L_{\lambda}=\text { gain } * \mathrm{DN}_{\lambda}+\text { bias, for Landsat } \mathrm{TM} \text { data. }
$$

In these equations, $L_{\lambda}$ is the apparent at-satellite radiance for spectral band $\lambda, \mathrm{DN}_{\lambda}$ is the digital number for band $\lambda, A_{\lambda}$ is the calibration factor for spectral band $\lambda$ of the HRG image, and $R_{\lambda}$ is the calibrated reflectance. $L_{\lambda}$.haze is path radiance, $\operatorname{Esun}_{\lambda}$ is exo-atmospheric solar irradiance, $\mathrm{D}$ is the distance between Earth and the Sun, and $\theta$ is the Sun zenith angle. The path radiance for each band was identified based on the analysis of water bodies and shades in the images.

\section{Wavelet-merging Technique}

Images from different sensors contain distinctive features. Integration of multi-sensor or multiresolution data takes advantage of the strengths of distinct image data for improvement of visual interpretation and quantitative analysis. Solberg et al. (1996) broadly divided data fusion methods into four categories: statistical, fuzzy logic, evidential reasoning, and neural network. Pohl and Van Genderen (1998) provided a literature review on the methods of multi-sensor data fusion. Of the many approaches, the intensity-hue-saturation (IHS) transform may be the most frequently used method for improving visual display of multi-sensor data (Welch and Ehlers, 1987). However, the IHS approach can only employ three image bands and the resultant image may not be suitable for further quantitative analysis, such as classification. Principal component analysis (PCA) is often used for data fusion because it can produce an output that can better preserve the spectral integrity of the input dataset. In recent years, the waveletmerging technique has shown to be another effective approach to generate a better improvement of spectral and spatial information contents (Li et al., 2002; Ulfarsson et al., 2003). Hence, the wavelet-merging technique was used in this research to integrate TM or HRG multispectral bands and the HRG panchromatic band.

The wavelet theory is similar to Fourier transform analysis, but the wavelet transform uses short, discrete wavelets, instead of long continuous waves as in Fourier transforms. One key step in wavelet transform is to select the mother wavelet. The input image is broken down into successively smaller multiples of the mother wavelet. The derived wavelets have many mathematically useful characteristics that make them preferable to simple sine or cosine functions. Once the mother wavelet is defined, a family of multiples is created with incrementally increasing frequency. Then, the image is decomposed by applying coefficients to each of the waveforms. In theory, an image can be decomposed into high-frequency and low-frequency components. The low-frequency image is the lower spatial resolution image and the high-frequency image is the higher spatial resolution image containing the details of 
the image. In general, the high spatial resolution image is a single band, such as an HRG panchromatic band in this study. Figure 3 illustrated the concept of data fusion with the discrete wavelet transform based on multi-resolution images. In order to integrate the high spatial information into the multispectral image, it is necessary to select one image from the multispectral image to replace the low-frequency image from the wavelet transform. Different transforms, such as IHS or PCA can be used to create a new image from the multispectral image. In this research, PCA was used to convert the multi-spectral bands into a new dataset and the first principal component (PC1) was used to replace the low-frequency image, because PC1 contained most of the information. A detailed description of the wavelet-merging technique is found in Lemeshewsky (1999) and the ERDAS Field Guide (ERDAS, 2003). During wavelet-merging processing based on TM data, TM bands 1 and 7 were not used because of the high correlations between TM- 1 and two other visible bands and between TM SWIR bands 5 and 7. Also, the wavelengths of HRG multispectral bands correspond to TM bands 2 to 5 .

\section{Texture Analysis}

Previous research has indicated that the grey-level co-occurrence matrix (GLCM) texture measures are important in improving land-cover classification accuracies (Gong et al., 1992; Shaban and Dikshit, 2001). However, for a specific study area, it is often difficult to identify a suitable textural image because it varies with the characteristics of the landscape under investigation, the texture measure selected, the size of the moving window, and the image band (Franklin et al., 1996; Chen et al., 2004). The difficulty in identifying suitable textural images and the computation cost for calculating textures limit extensive use of textures in image classification, especially over a large area. In this research, eight texture measures (i.e., mean, variance, homogeneity, contrast, dissimilarity, entropy, second moment, and correlation) with nine sizes of moving windows $(3 \times 3,5 \times 5,7 \times 7,9 \times 9,11 \times 11,15 \times 15,19 \times 19,25 \times 25$, and $31 \times 31$ ) on the HRG panchromatic band were examined. Because not all textural images are useful in improving vegetation classification performance, it is necessary to identify the best textural images that can maximize the separation of vegetation classes. Therefore, the textural images were rescaled to an 8-bit integer format ( 0 to 255 ). The texture feature for each training sample plot was extracted, and separability was analyzed using a transformed divergence (TD) algorithm (Mausel et al., 1993; Landgrebe, 2003). The textural images with TD values greater than 1,900 were initially selected for further analysis. Pearson's correlation analysis was used to analyze the correlation coefficients for the initially selected textural images. The textural images with high separability and low correlation coefficients were finally selected. If two or more textural images were used, the following equation was used to identify the best textural image combination:

$$
\text { Best Texture Combination (BTC) }=\sum_{i=1}^{n} T D_{i} / \sum_{j=1}^{n} R_{i j} \text {, }
$$

where $T D_{i}$ is the transformed divergence value based on the training sample plots on the textural image $i, R_{i j}$ is the correlation coefficient between two textural images $i$ and $j$, and $n$ is the number of textural images.

\section{Analysis of Image Classification Results}

The potential images used for image classification included TM or HRG multispectral images, the data-fused images based on TM (or HRG) multispectral and HRG panchromatic images, the combinations of HRG multispectral and textural images (from one to four), and the combinations of HRG multispectral and panchromatic data-fused images and textural images 
(from one to four). The image classifications based on the extensive combinations attempted to answer the following questions:

1. Comparing HRG and TM multispectral images, can the HRG image, with its higher spatial resolution, improve vegetation classification performance?

2. Comparing data-fused images between TM multispectral and HRG panchromatic images and between HRG multispectral and panchromatic images, which one can provide better vegetation classification accuracy? Can the data-fused images improve the vegetation classification accuracy comparing their original multispectral images?

3. Can incorporation of textural images as extra bands into multispectral images improve vegetation classification performance? Can incorporation of textural images into HRG multispectral-panchromatic data-fused images further improve vegetation classification accuracy? How many textural images are suitable?

Before implementing image classification, all images, including multispectral and textural, were rescaled to 8-bit integer format (0 to 255). Then non-vegetation types (e.g., water, urban and residential area, and bare soils) were masked, based on the analysis of an unsupervised classification (ISODATA) image on the HRG multispectral image. In the vegetated areas, a classification system with nine vegetation types was adopted (see Table 1 for the characteristics of each vegetation type). About 12 to 20 sample plots were selected for each class, with a polygon size of 9 to 40 pixels being used for each plot depending on the homogeneity of the vegetation type. A maximum likelihood classier was then used to classify each combined image. The same training sample plots were used to implement image classification for each image combination.

In order to evaluate the classification accuracy for each image combination, a common method for accuracy assessment is through the use of an error matrix. Previous literature has provided the meanings and calculation methods for overall accuracy, producer's accuracy, user's accuracy, and kappa coefficient (Congalton, 1991; Smits et al., 1999; Foody, 2002). In this study, a total of 306 test samples were used for accuracy assessment. Most of these test plots were collected during fieldwork in 2002 and 2003. The HRG and Ikonos color composites were also used to collect more test samples based on visual interpretation. The second author has studied this area for more than a decade and collected extensive datasets through LBA and Embrapa projects, which is important for the validation of the classification procedures. The producer's accuracy and user's accuracy for each class, and overall accuracy and kappa coefficient for each image combination were calculated based on the error matrix.

\section{Results}

\section{Analysis of Textural Images}

Different texture measures have various capabilities in separating vegetation classes. Different sizes of the moving window on the same texture measure also affect this capability. Therefore, there exists a best combination of texture measure and size of moving window suitable for the separation of vegetation classes. Table 2 summarized the separability analysis results of 72 test cases. It indicates that the size of the moving window is important in the separability of vegetation classes. The best window size varies, depending on the use of texture measures. For example, the best sizes for entropy and second-moment texture measures were $9 \times 9$ and $11 \times$ 11 , respectively, but for dissimilarity and contrast texture measures, the best window sizes were $15 \times 15$ and $25 \times 25$, respectively. In general, window sizes that were too small, such as $3 \times 3$ and $5 \times 5$, or too large, such as $31 \times 31$, produced poor separability of vegetation classes. Some texture measures, such as entropy and second-moment texture measures, provided better 
separability of vegetation classes than others, such as variance and correlation texture measures.

Visual analysis of the textural images indicated that some textural images provided very similar textural information, implying that not all textural images were needed in vegetation classification. Our analysis of the correlation coefficients between the textural images indicated that the textural images from the same texture measure but different window sizes were strongly correlated; for example, the coefficient between two textural images from entropy with $9 \times 9$ and $11 \times 11$ windows was as high as 0.97 . On the other hand, some different texture measures with similar window sizes were also strongly correlated, such as between entropy, dissimilarity, and second moment because they highlighted the similar (or homogeneous) information. The analysis of Best Texture Combination (BTC) helps identify the textural images with the best capability in vegetation separation but less correlation each other. The identified four textural images were from the entropy texture measure with a window size of $9 \times 9$, the second moment with $11 \times 11$, dissimilarity with $15 \times 15$, and contrast with $25 \times 25$ (Figure 4). The selected four textural images have a common feature: highlighting the linear features such as roads and boundaries between land-covers. The selected textural images were then incorporated into spectral features as extra bands to explore their roles in improving vegetation classification performance.

\section{Analysis of Image Classification Results}

Higher spatial resolution images have an important role in improving successional vegetation classification accuracy, while relatively lower spatial resolution images are helpful for the primary forest classification (Table 3). For example, HRG images (e.g., HRG-MS and HRGFusion) provided higher classification accuracies in SS1, SS2, and SS3 than TM images, but TM images (e.g., TM-2-3-4-5 and TM-ALL) provided higher classification accuracies for the upland dense forest and flooding forests. Higher spatial resolution in HRG multispectral images reduced the mixed pixel problem, resulting in improved successional vegetation classification accuracy, but higher spatial resolution also increased spectral variations, especially in primary forests, because of their complex forest stand structure and canopy shadows, resulting in poor classification accuracies. In this situation, relatively lower spatial resolution images such as TM with 30-meter spatial resolution reduced the spectral variation within the primary forests, thus produced better classification accuracy, but this spatial resolution image included mainly mixed pixels for the successional vegetation.

Interesting to note in Table 3 is that the HRG multispectral and panchromatic data-fused images slightly improved overall classification accuracy, but the TM multispectral and HRG panchromatic data-fused images significantly reduced the overall classification accuracy (61.8 percent for HRG-Fusion versus 52.9 percent for TM-Fusion). The TM-Fusion approach especially decreased the classification accuracies of SS2, SS3, DGP, AGF, and UOF. Although the TM multispectral and HRG panchromatic data-fused image improved visual interpretation effects, the large difference in spatial resolutions between TM and HRG panchromatic images ( $30 \mathrm{~m}$ versus $5 \mathrm{~m}$ ) exaggerated spectral variations within the same land-cover classes and introduced noise in the fused images, thus reducing image classification performance. This implies that direct use of the data-fused images without further image processing to remove the noise is not suitable for vegetation classification.

Overall, the HRG-Fusion provided the best classification accuracies of 61.8 percent for nine vegetation classes, a 3.1 percent increase in kappa coefficient compared with HRG-MS, and 4.6 percent increase compared with the TM-ALL approach. Comparing TM-2-3-4-5 and TMALL images, although both have similar overall classification accuracy (approximately 58 percent), the TM-2-3-4-5 data provided slightly better classification accuracies for most of the 
vegetation classes than TM-ALL data, implying that the addition of more spectral bands with high correlation coefficients to each other may decrease classification accuracy.

Incorporation of textural and multispectral images improved vegetation classification performance (Table 4). For example, the combination of entropy texture image and HRG multispectral image (MS-Txt1) improved the vegetation classification accuracies for all except SS1. Overall classification accuracy and kappa coefficient were increased by 5.2 percent and 5.8 percent, respectively, compared with the results from the original HRG multispectral image. The incorporation of textural images and HRG-Fusion images, as well as two textural and HRG multispectral images (MS-Txt2) can further improve the classification accuracy. However, use of more textural images (e.g., MS-Txt3, MS-Txt4, or Fusion-Txt3 and Fusion-Txt4) cannot further improve classification accuracy because of the correlation between the images. Table 4 also indicates that use of textural images was especially helpful in improving primary forest classification. This implies that textural images can reduce the spectral variations of primary forests caused by complex forest stand structure and canopy shadows in the high spatial resolution image.

\section{Discussion}

The complex biophysical environments in the moist tropical region may be the most important factor resulting in the difficulty of vegetation classification. Based on the vegetation vertical structure complexity (Lu, 2005a), a concept showing the relationships among the vegetation types is illustrated in Figure 5. Degraded pastures can be regarded as a transition between cultivated pastures and SS1, because some saplings and seedlings appeared in degraded pastures indicating the degraded pastures may become SS1 after a couple years, if they are not properly managed. Also, if no disturbance occurs, SS1 will progress to SS2 and then to SS3. However, there are no clear boundaries between the adjacent stages that separate SS2 from SS1 and SS3 because of the smooth transitions in their vegetation stand structures. Therefore, classification of successional vegetation stages is often difficult, even on the ground. Another difficulty is separating AGF from successional vegetations. The agroforestry/perennial agriculture class can include a variety of vegetation types, from coffee, cocoa, or rubber tree plantations to arrangements of many plants, including successional and economic species. This class is often confused with different successional stages, especially SS2. Also, agroforestry/ perennial agriculture and different successional vegetation stages usually appeared in small patches in the landscape (i.e., 0.5 to 3 ha). This implies that most of these vegetation types appear on Landsat TM images as mixed pixels. This often results in difficulty in collecting sufficient and suitable training and test samples for these vegetation classes. The trend toward land-use intensification has reduced the extension of successional vegetation patches and shortened the cycle of conversion of fallow areas into agricultural production. Thus, use of subpixel information benefit these vegetation classification accuracies (Roberts et al., 2002; Lu et al., 2003b). In this study area, lack of typical SS3 samples is another important factor resulting in poor SS3 classification accuracy. The selected SS3 samples are mainly in early stages of advanced secondary succession and often confused with old SS2 vegetation because of their similar vegetation stand structure. The limitation in finding SS3 areas also created difficulties for the selection of sufficient test sample plots for accuracy assessment. In this situation, the use of expert rules based on the forest stand structure can significantly improve the classification accuracies (Lu, 2005a).

Classification of primary forests into multiple classes is also a challenge because the similar forest stand structures and the influence of canopy shadows which leads to data saturation in optical remote-sensing data. However, the abundant moisture can reduce the reflectance values of flooding forests. Poor soil conditions and the topographic effects of upland open forests on steep slopes may produce different tree species composition and vegetation vigor compared to 
upland dense forests. Conversely, non-forest vegetations (e.g., successional vegetations, agroforestry) are usually distributed in relatively flat areas with easy access. Topography and moisture are not important factors in separating successional vegetation stages in this study area.

The optical sensor data, such as Landsat TM and SPOT HRG that mainly capture canopy and associated shadow information, create difficulties in vegetation classification. The shadow problem often reduces vegetation reflectance, and the complex forest stand structure causes data saturation making it difficult to classify forest and advanced successional vegetation classes, even though their biomass densities may vary significantly (Lu, 2005b). Use of radar data, especially the long wavelengths such as L- and P-bands, may improve the vegetation classification because radar can penetrate the canopy to a certain depth to capture more information under the canopy (Leckie, 1998; Santos et al., 2003). The integration of optical sensor and radar data may provide new insights for vegetation classification in the moist tropical regions.

This research has shown the importance of high spatial resolution images in improving vegetation classification accuracies, especially the successional vegetation. High spatial resolution images greatly reduce the mixed pixel problem because non-forest vegetation often has small patch sizes on the ground. On the other hand, high spatial resolution images have rich spatial information, but also show high spectral variation within the same land-cover class. Effective use of spatial information and reduction of the impacts of spectral variation are critical for improving overall classification performance. This study has indicated the importance of textural images in improving vegetation classification accuracies. One critical step in a study is to identify suitable textural images that can provide the best separability for the specified classes. However, selection of suitable textural images is still a challenge, because textures vary with the characteristics of the landscape under investigation and images used. In particular, the selection of a suitable size of moving window is important for a textural image, but no window size is perfect for all vegetation types because the field sizes of the vegetation types vary greatly, i.e., from less than one hectare for some successional vegetation and agroforestry to hundreds of hectares for some primary forests. Therefore, there are tradeoffs among moving window size, spatial resolution of images, and the sizes of vegetation types on the ground. For this study, the selection of window size is based on the overall separability of vegetation types, but the best window size for extraction of textural images for the separation of non-forest vegetation types and the separation of primary forest classes may vary because of their different vegetation stand structures and patch sizes. A stratification of primary forests and non-forest vegetation types may be necessary before the selection of suitable textural images. Two approaches may be used to evaluate the textural images: qualitative assessment based on visual interpretation to see whether the specified information was highlighted or not on the selected textural image; and quantitative analysis, such as the calculation of separability of vegetation classes based on training samples, as used in this paper. For the selection of a single textural image, one can select the textural image with highest separability, but for the selection of two or more textural images, the BTC approach developed in this paper provides an easy way to identify the suitable combination of textural images that can be used for improving classification performance.

\section{Conclusions}

High spatial resolution images benefit the classification of successional vegetation stages, and relatively low spatial resolution is useful for primary forests. The incorporation of textural images into an HRG multispectral image is an effective approach to improve vegetation classification performance. The entropy or second-moment texture measure with a window size of $9 \times 9$ or $11 \times 11$ pixels provided the best separability for vegetation classes. Overall, 
vegetation classification with optical sensor data in the moist tropical region remains difficult, especially for the separation of different successional vegetation stages and the separation of agroforestry from other non-forest vegetation types. More research is needed to incorporate optical sensor and radar data to improve vegetation classification.

\section{Acknowledgments}

The authors wish to thank the three anonymous reviewers for their constructive suggestions and comments. The authors also thank the National Science Foundation (Grant \#99-06826), the National Aeronautics and Space Administration (Grant \#NCC5-695), and the Brazil's Embrapa Satellite Monitoring for their support. This project is part of the Large Scale Biosphere-Atmosphere Experiment in Amazônia (LBA) Program, LC-09 and LC-34, which aims to examine the human and physical dimensions of land-use/land-cover change.

\section{References}

Adams JB, Sabol DE, Kapos V, Filho RA, Roberts DA, Smith MO, Gillespie AR. Classification of multispectral images based on fractions of endmembers: Application to land-cover change in the Brazilian Amazon. Remote Sensing of Environment 1995;52:137-154.

Batistella, M. PhD dissertation. Indiana University, Bloomington; Indiana: 2001. Landscape Change and Land-use/Land-cover Dynamics in Rondônia, Brazilian Amazon; p. 399

Batistella M, Robeson S, Moran EF. Settlement design, forest fragmentation, and landscape change in Rondônia, Amazônia. Photogrammetric Engineering \& Remote Sensing 2003;69:805-812.

Batistella M, Moran EF. Dimensões humanas do uso e cobertura das terras na Amazônia: Uma contribuição do LBA. Acta Amazonica 2005;35:239-247.

Bognola, IA.; Soares, AF. Pesquisa em Andamento. Vol. 10. Embrapa Monitoramento por Satélite; Campinas, Brazil: 1999. Solos das "glebas 01, 02, 03 e 06" do Município de Machadinho d'Oeste, RO; p. 7

Brondízio ES, Moran EF, Mausel P, Wu Y. Land cover in the Amazon estuary: Linking of the Thematic Mapper with botanical and historical data. Photogrammetric Engineering \& Remote Sensing 1996;62 (9):921-929.

Canty MJ, Nielsen AA, Schmidt M. Automatic radiometric normalization of multitemporal satellite imagery. Remote Sensing of Environment 2004;91:441-451.

Chavez PS Jr. Image-based atmospheric corrections Revisited and improved. Photogrammetric Engineering \& Remote Sensing 1996;62(10):1025-1036.

Chen D, Stow DA, Gong P. Examining the effect of spatial resolution and texture window size on classification accuracy: An urban environment case. International Journal of Remote Sensing 2004;25:2177-2192.

Congalton RG. A review of assessing the accuracy of classification of remotely sensed data. Remote Sensing of Environment 1991;37:35-46.

ERDAS. ERDAS Field Guide. Vol. 7. Leica Geosystems GIS \& Mapping, LLC; Atlanta, Georgia: 2003.

Foody GM, Palubinskas G, Lucas RM, Curran PJ, Honzák M. Identifying terrestrial carbon sinks: Classification of successional stages in regenerating tropical forest from Landsat TM data. Remote Sensing of Environment 1996;55:205-216.

Foody GM. Status of land cover classification accuracy assessment. Remote Sensing of Environment 2002;80:185-201.

Franklin SE, Wulder MA, Lavigne MB. Automated derivation of geographic window sizes for remote sensing digital image texture analysis. Computers and Geosciences 1996;22:665-673.

Gong P, Marceau DJ, Howarth PJ. A comparison of spatial feature extraction algorithms for land-use classification with SPOT HRV data. Remote Sensing of Environment 1992;40:137-151.

Haack BN, Solomon EK, Bechdol MA, Herold ND. Radar and optical data comparison/integration for urban delineation: A case study. Photogrammetric Engineering \& Remote Sensing 2002;68(12): 1289-1296.

Haralick RM, Shanmugam K, Dinstein I. Textural features for image classification. IEEE Transactions on Systems, Man and Cybernetics 1973;SMC-3:610-620. 
Kashyap RL, Chellappa R, Khotanzad A. Texture classification using features derived from random field models. Pattern Recognition Letters 1982;1:43-50.

Landgrebe, DA. Signal Theory Methods in Multispectral Remote Sensing. Hoboken, New Jersey: John Wiley and Sons; 2003. p. 508

Laurance W, Albernaz AKM, Fearnside PM, Vasconcelos HL, Ferreira LV. Deforestation in Amazonia. Science 2004;304:1109. [PubMed: 15155931]

Leckie, DG. Forestry applications using imaging radar. In: Henderson, FM.; Lewis, AJ., editors. Principles and Applications of Imaging Radar, Manual of Remote Sensing. Vol. 3. Vol. 2. John Wiley and Sons; New York: 1998. p. 437-509.

Lemeshewsky, GP. Multispectral multisensor image fusion using wavelet transforms. In: Park, SK.; Juday, R., editors. Visual Image Processing VIII; Proceedings of SPIE 3716; 1999. p. 214-222.

Li S, Kwok JT, Wang Y. Using the discrete wavelet frame transform to merge Landsat TM and SPOT panchromatic images. Information Fusion 2002;3:17-23.

Lu D. Integration of vegetation inventory data and Landsat TM image for vegetation classification in the western Brazilian Amazon. Forest Ecology and Management 2005a;213:369-383.

Lu D. Aboveground biomass estimation using Landsat TM data in the Brazilian Amazon. International Journal of Remote Sensing 2005b;26:2509-2525.

Lu D, Mausel P, Brondízio E, Moran E. Assessment of atmospheric correction methods for Landsat TM data applicable to Amazon basin LBA research. International Journal of Remote Sensing 2002;23:2651-2671.

Lu D, Mausel P, Brondízio E, Moran E. Classification of successional forest stages in the Brazilian Amazon basin. Forest Ecology and Management 2003a;181:301-312.

Lu D, Moran E, Batistella M. Linear mixture model applied to Amazônian vegetation classification. Remote Sensing of Environment 2003b;87:456-469.

Lu D, Mausel P, Batistella M, Moran E. Comparison of land-cover classification methods in the Brazilian Amazon basin. Photogrammetric Engineering \& Remote Sensing 2004;70(7):723-731.

Lucas RM, Honzák M, Curran PJ, Foody GM, Milne R, Brown T, Amaral S. The regeneration of tropical forests within the Legal Amazon. International Journal of Remote Sensing 2000;21:2855-2881.

Marceau DJ, Howarth PJ, Dubois JM, Gratton DJ. Evaluation of the grey-level co-occurrence matrix method for land-cover classification using SPOT imagery. IEEE Transactions on Geoscience and Remote Sensing 1990;28:513-519.

Mausel P, Wu Y, Li Y, Moran E, Brondízio E. Spectral identification of succession stages following deforestation in the Amazon. Geocarto International 1993;8:61-72.

Moran EF, Brondízio E, Mausel P, Wu Y. Integrating Amazonian vegetation, land use, and satellite data. Bioscience 1994;44:329-338.

Pohl C, van Genderen JL. Multisensor image fusion in remote sensing: Concepts, methods, and applications. International Journal of Remote Sensing 1998;19:823-854.

Roberts DA, Numata I, Holmes K, Batista G, Krug T, Monteiro A, Powell B, Chadwick OA. Large area mapping of land-cover change in Rondonia using decision tree classifiers. Journal of Geophysical Research 2002;107(D20):8073 LBA 40-1-40-18.

Rondônia. Diagnóstico Sócio-econômico do Estado de Rondônia e Assistência Técnica para Formulação da Segunda Aproximação do Zoneamento Sócio-econômico-ecológico - Climatologia. Vol. 1. Governo de Rondônia/PLANAFLORO; Porto Velho, Brasil: 1998.

Santos JR, Freitas CC, Araujo LS, Dutra LV, Mura JC, Gama FF, Soler LS, Sant' Anna SJS. Airborne P-band SAR applied to the aboveground biomass studies in the Brazilian tropical rainforest. Remote Sensing of Environment 2003;87:482-493.

Shaban MA, Dikshit O. Improvement of classification in urban areas by the use of textural features: The case study of Lucknow city, Uttar Pradesh. International Journal of Remote Sensing 2001;22:565593.

Shaban MA, Dikshit O. Evaluation of the merging of SPOT multispectral and panchromatic data for classification of an urban environment. International Journal of Remote Sensing 2002;23:249-262.

Skole DL, Chomentowski WH, Salas WA, Nobre AD. Physical and human dimension of deforestation in Amazonia. BioScience 1994;44:314-328. 
Smits PC, Dellepiane SG, Schowengerdt RA. Quality assessment of image classification algorithms for land-cover mapping: A review and a proposal for a cost-based approach. International Journal of Remote Sensing 1999;20:1461-1486.

Solberg AHS, Taxt T, Jain AK. A Markov random field model for classification of multisource satellite imagery. IEEE Transactions on Geoscience and Remote Sensing 1996;34:100-112.

Song C, Woodcock CE, Seto KC, Lenney MP, Macomber SA. Classification and change detection using Landsat TM data: When and how to correct atmospheric effect. Remote Sensing of Environment 2001;75:230-244.

Tokola T, Löfman S, Erkkilä A. Relative calibration of multitemporal Landsat data for forest cover change detection. Remote Sensing of Environment 1999;68:1-11.

Ulfarsson MO, Benediktsson JA, Sveinsson JR. Data fusion and feature extraction in the wavelet domain. International Journal of Remote Sensing 2003;24:3933-3945.

Vermote E, Tanre D, Deuze JL, Herman M, Morcrette JJ. Second simulation of the satellite signal in the solar spectrum, 6S: An overview. IEEE Transactions on Geoscience and Remote Sensing 1997;35:675-686.

Vieira ICG, de Almeida AS, Davidson EA, Stone TA, de Carvalho CJR, Guerrero JB. Classifying successional forests using Landsat spectral properties and ecological characteristics in eastern Amazonia. Remote Sensing of Environment 2003;87:470-481.

Welch R, Ehlers M. Merging multi-resolution SPOT HRV and Landsat TM data. Photogrammetric Engineering \& Remote Sensing 1987;53(3):301-303.

Yocky DA. Multiresolution wavelet decomposition image merger of Landsat Thematic Mapper and SPOT panchromatic data. Photogrammetric Engineering \& Remote Sensing 1996;62(10):10671074. 


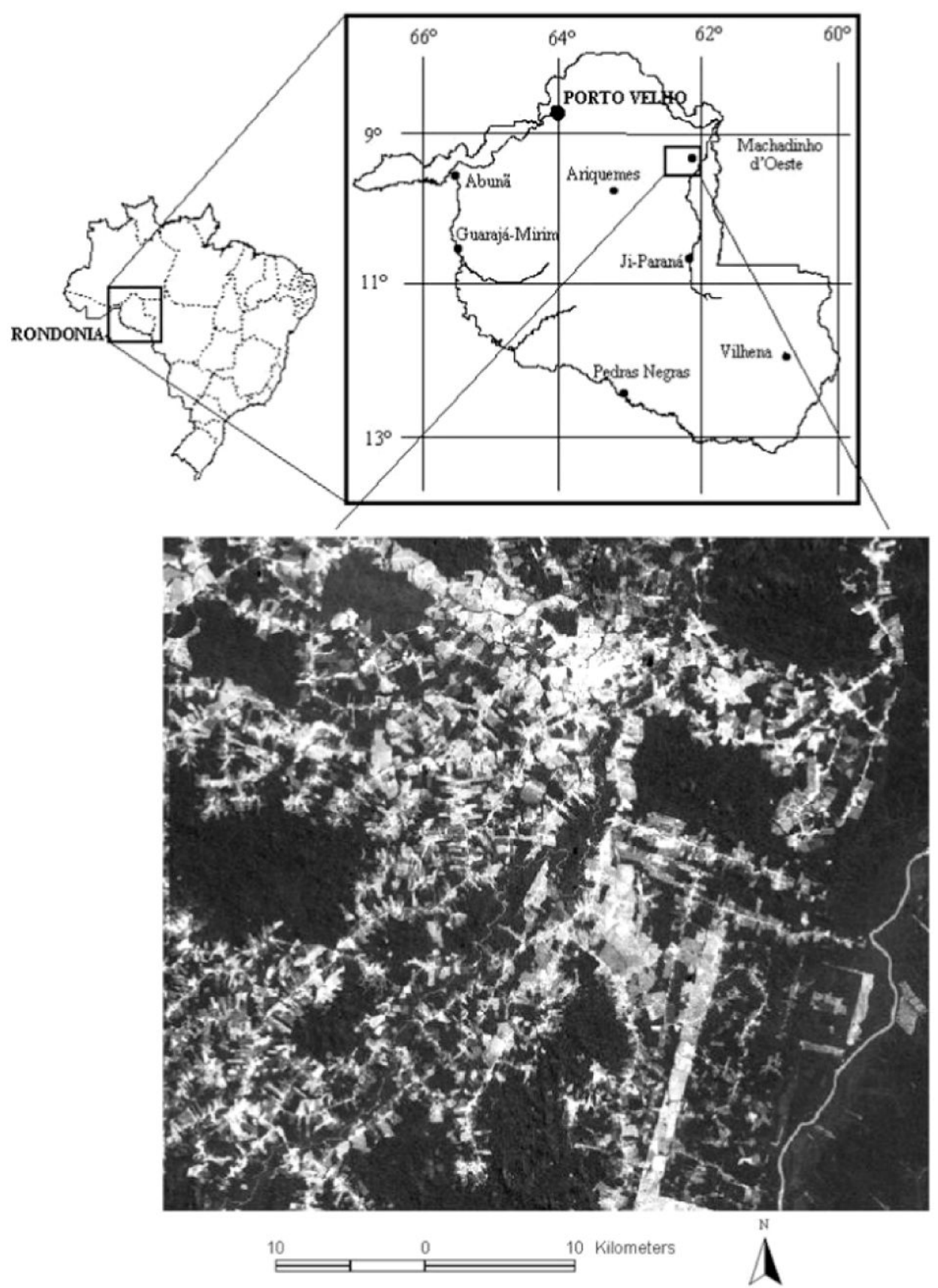

Figure 1.

Location of the study area: Machadinho d'Oeste in the state of Rondônia, Brazil. 
Study Area Nested subplots

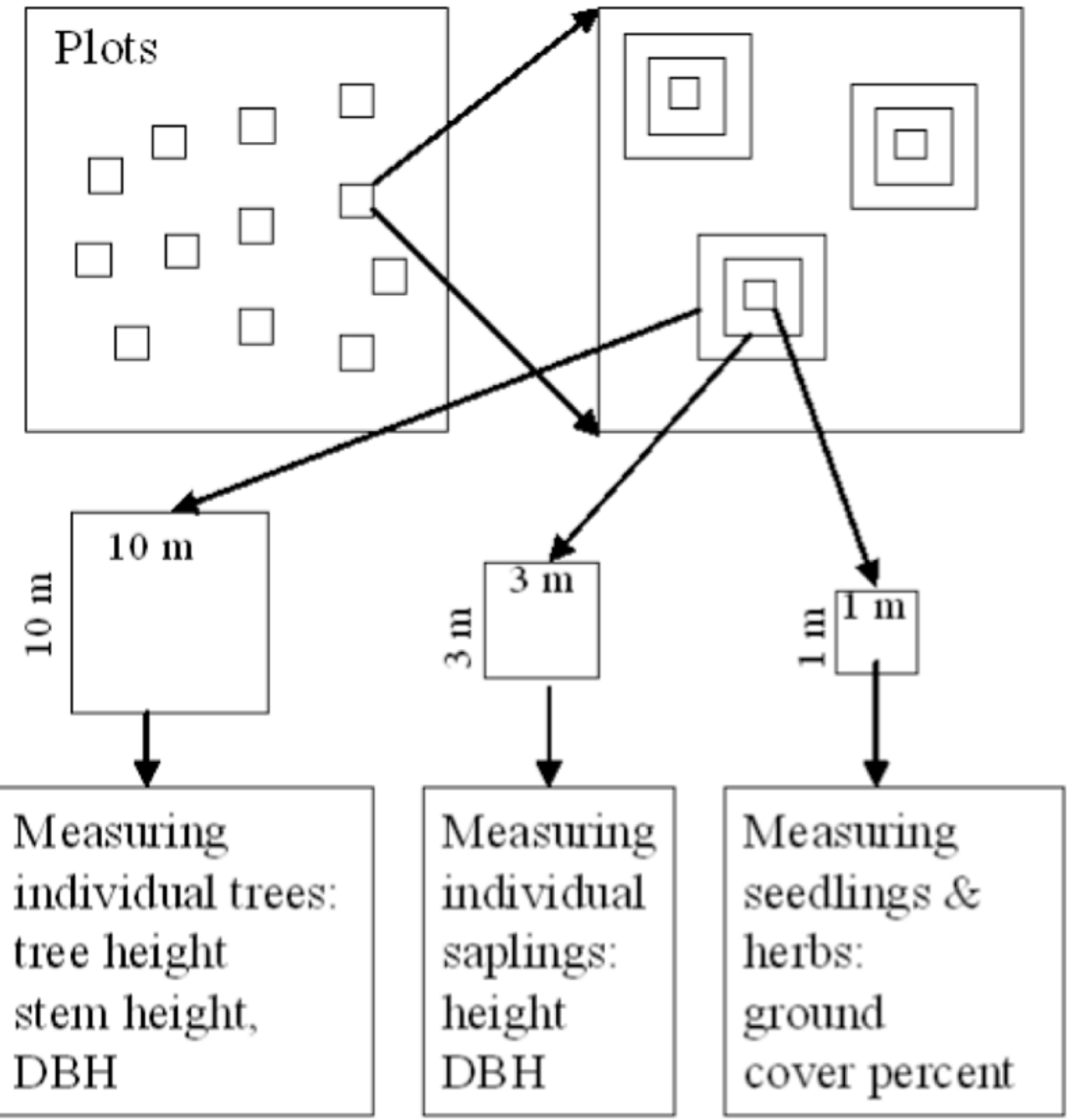

Figure 2.

Strategy of field data collection for successional vegetation and primary forests. 


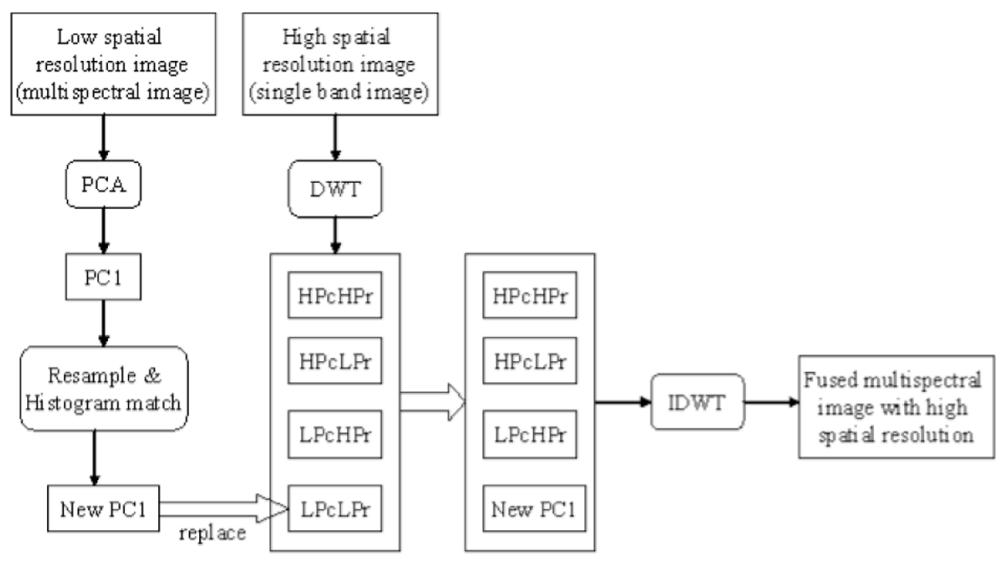

Figure 3.

Wavelet-merging approach based on multiple spatial resolution images (PCA and PC1 represent principal component analysis and the first principal component, DWT and IDWT represent discrete wavelet transform and inverse discrete wavelet transform, HP and LP represent high pass and low pass, and $\mathrm{c}$ and $\mathrm{r}$ represent column and row decimation) 


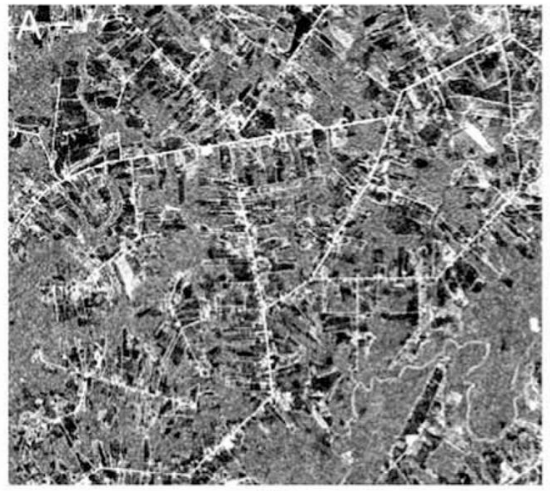

(a)

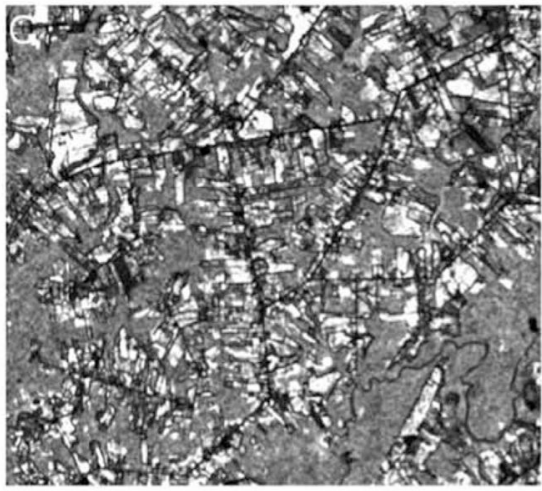

(c)

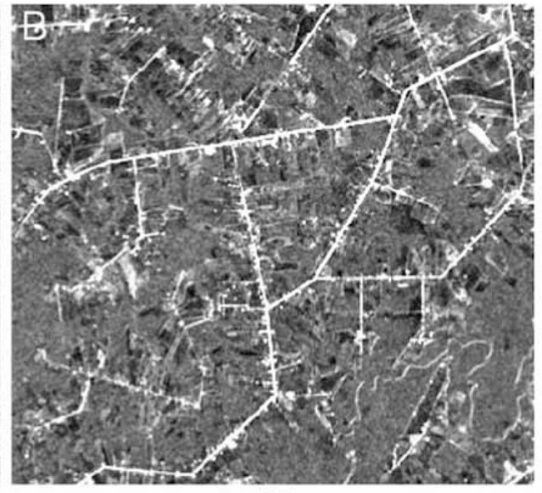

(b)

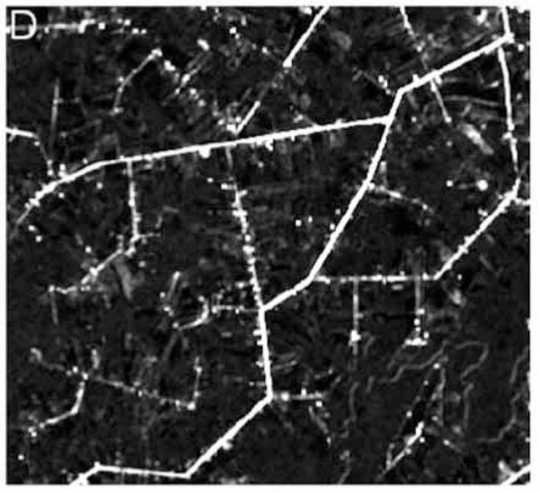

(d)

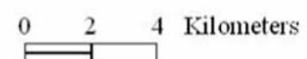

A

Figure 4.

Comparison of selected four textural images with corresponding window sizes based on the SPOT HRG panchromatic image (part of the study area): (a) entropy texture measure with 9 $\times 9$ window size, (b) dissimilarity texture measure with $15 \times 15$ window size, (c) second moment texture measure with $11 \times 11$ window size, and (d) contrast texture measure with 25 $\times 25$ window size. 


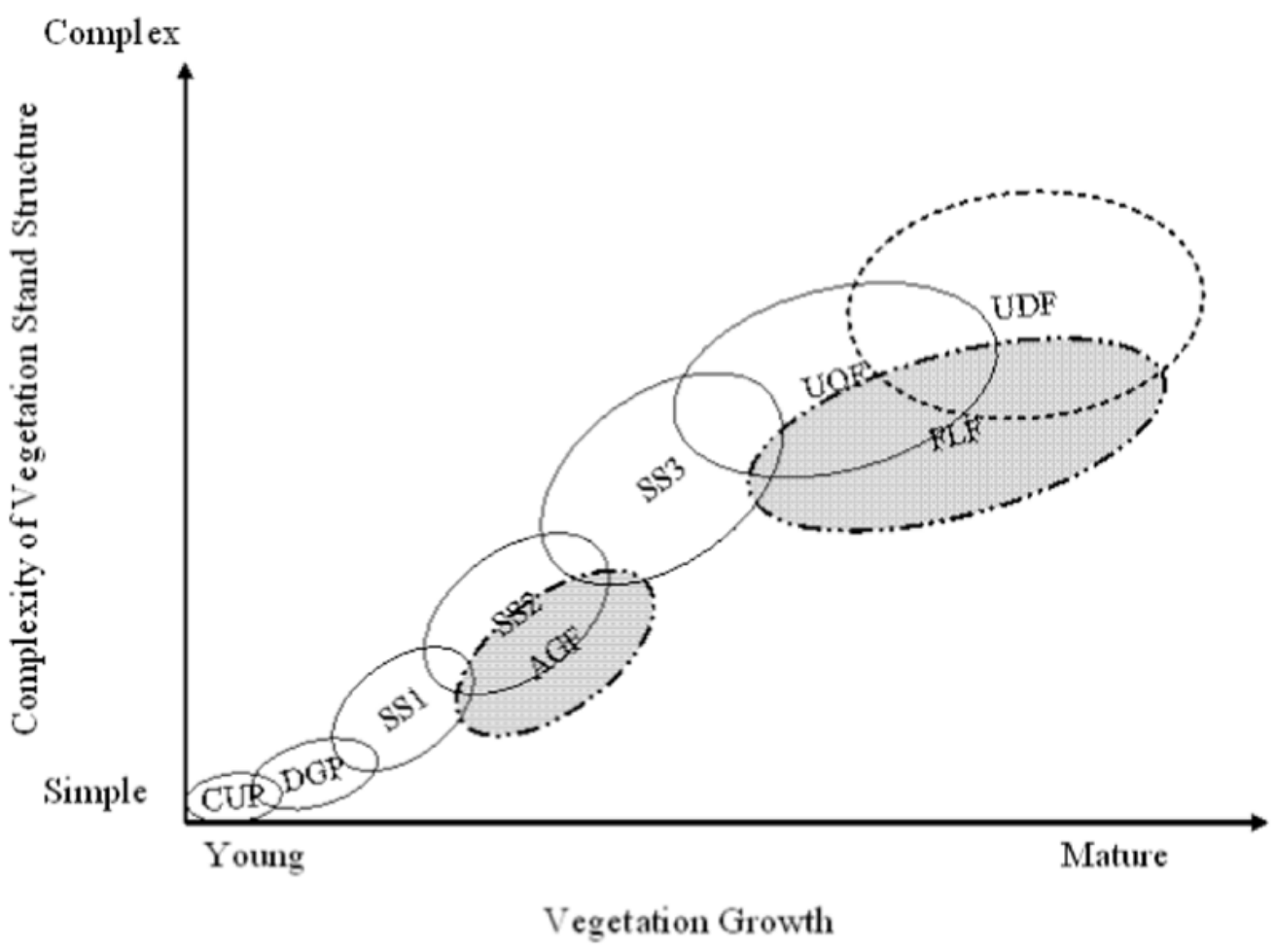

Figure 5.

A concept of vegetation stand structure complexity among different vegetation classes (CUP and DGP represent cultivated and degraded pastures; SS1, SS2, and SS3 represent initial, intermediate, and advanced successional vegetations; AGF represents agroforestry/perennial agriculture; UOF, UDP, and FLF represent upland open forest, upland dense forest, and flooding forest) 


\section{Characteristics of Vegetation Types}

Table 1

\begin{tabular}{|c|c|c|}
\hline Vegetation Types & Parameters & Main Characteristics \\
\hline Cultivated pasture (CUP) & Grass $>75 \%$ & Pastures managed to keep the dominance of grass species \\
\hline Degraded pasture (DGP) & $\begin{array}{l}\text { Grass ranges from } 25 \% \text { to } \\
75 \%\end{array}$ & Limited seedlings and saplings appeared in the ground \\
\hline Agroforestry/Perennial agriculture (AGF) & & $\begin{array}{l}\text { Coffee, rubber, banana, cacao plantations or their } \\
\text { association with other economic or non-economic species }\end{array}$ \\
\hline Initial succession ( $\mathrm{SS} 1)$ & $\begin{array}{l}\text { ASD: } 2 \text { to } 5 \\
\text { ASH: } 2 \text { to } 6 \\
\text { AGB: } 0.5 \text { to } 5 \\
\text { Age: } 1 \text { to } 5\end{array}$ & $\begin{array}{l}\text { Herbaceous plants, seedlings, and saplings together are } \\
\text { responsible for over } 90 \text { percent of total biomass, with a } \\
\text { vertical structure characterized by a full profile of saplings } \\
\text { and herbaceous plants. Saplings are the main structure } \\
\text { element and represent the majority of the aboveground } \\
\text { biomass. }\end{array}$ \\
\hline Intermediate succession (SS2) & $\begin{array}{l}\text { ASD: } 5 \text { to } 15 \\
\text { ASH: } 6 \text { to } 12 \\
\text { AGB: } 4 \text { to } 10 \\
\text { Age: } 4 \text { to } 15\end{array}$ & $\begin{array}{l}\text { Saplings still account for most of the biomass in SS2. } \\
\text { Vegetation structure provides a mix of dense ground cover } \\
\text { of saplings and young trees with higher canopy than SS1 } \\
\text { and small internal differences between canopy and } \\
\text { understory individuals. Stratification between canopy and } \\
\text { understory begins in SS2. }\end{array}$ \\
\hline Advanced succession (SS3) & $\begin{array}{l}\text { ASD: } 10 \text { to } 25 \\
\text { ASH: } 9 \text { to } 17 \\
\text { AGB: } 8 \text { to } 25 \\
\text { Age: } 10 \text { to } 50\end{array}$ & $\begin{array}{l}\text { Stratification is obvious in SS } 3 \text { with trees dominating the } \\
\text { canopy. In this stage, there is a major shift in structure that } \\
\text { differentiates understory from canopy individuals; that is, } \\
\text { the presence of saplings is less significant than that of } \\
\text { trees. One can find differences between the canopy and } \\
\text { understory in terms of height and density of species. }\end{array}$ \\
\hline Upland dense forest (UDF) & $\begin{array}{l}\text { ASD: } 17 \text { to } 30 \\
\text { ASH: } 12 \text { to } 25 \\
\text { AGB: } 20 \text { to } 50\end{array}$ & $\begin{array}{l}\text { In a typical primary forest, trees account for the majority } \\
\text { of the aboveground biomass, reaching over } 90 \text { percent. } \\
\text { Large trees occupy the canopy. Trees with DBH of } 25 \text { to } \\
30 \mathrm{~cm} \text { dominate, and a considerable number of individuals } \\
\text { have a DBH over } 40 \mathrm{~cm} \text {. Many tree individuals are taller } \\
\text { than } 17 \mathrm{~m} \text { and some between } 25 \text { and } 30 \mathrm{~m} \text { are present, } \\
\text { followed by a few scattered emergent individuals over } 35 \\
\mathrm{~m} \text { high. }\end{array}$ \\
\hline Upland open forest (UOF) & $\begin{array}{l}\text { ASD: } 12 \text { to } 20 \\
\text { ASH: } 10 \text { to } 15 \\
\text { AGB: } 10 \text { to } 20\end{array}$ & $\begin{array}{l}\text { Usually located in the areas with steep slopes and poor soil } \\
\text { conditions }\end{array}$ \\
\hline Flooding forest (FLF) & Similar with UDF & $\begin{array}{l}\text { Usually located along water courses with seasonal } \\
\text { flooding conditions }\end{array}$ \\
\hline
\end{tabular}

Note: ASD and ASH represent average stand diameter $(\mathrm{cm})$ and average stand height $(\mathrm{m})$, AGB means aboveground biomass $\left(\mathrm{kg} / \mathrm{m}^{2}\right)$, and DBH means diameter at breast height. 


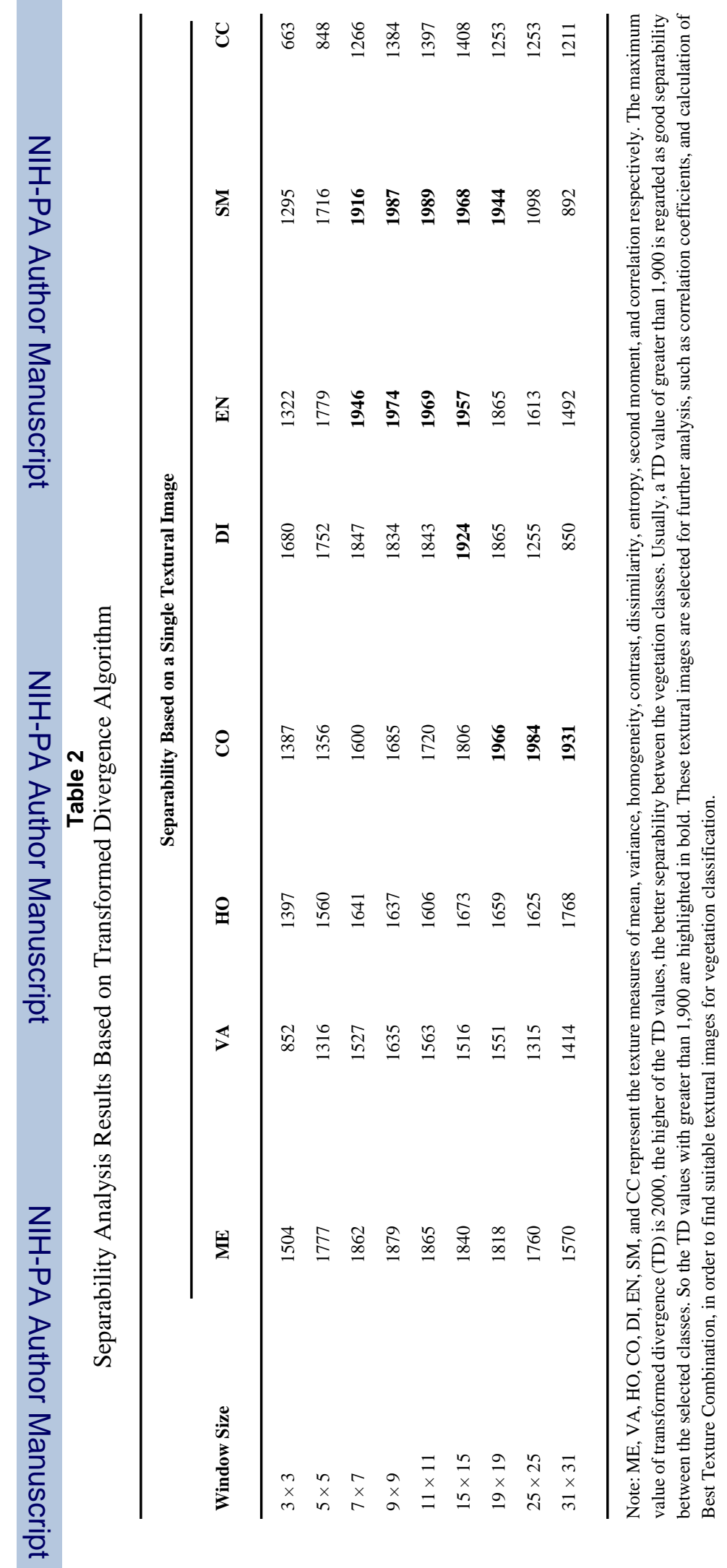




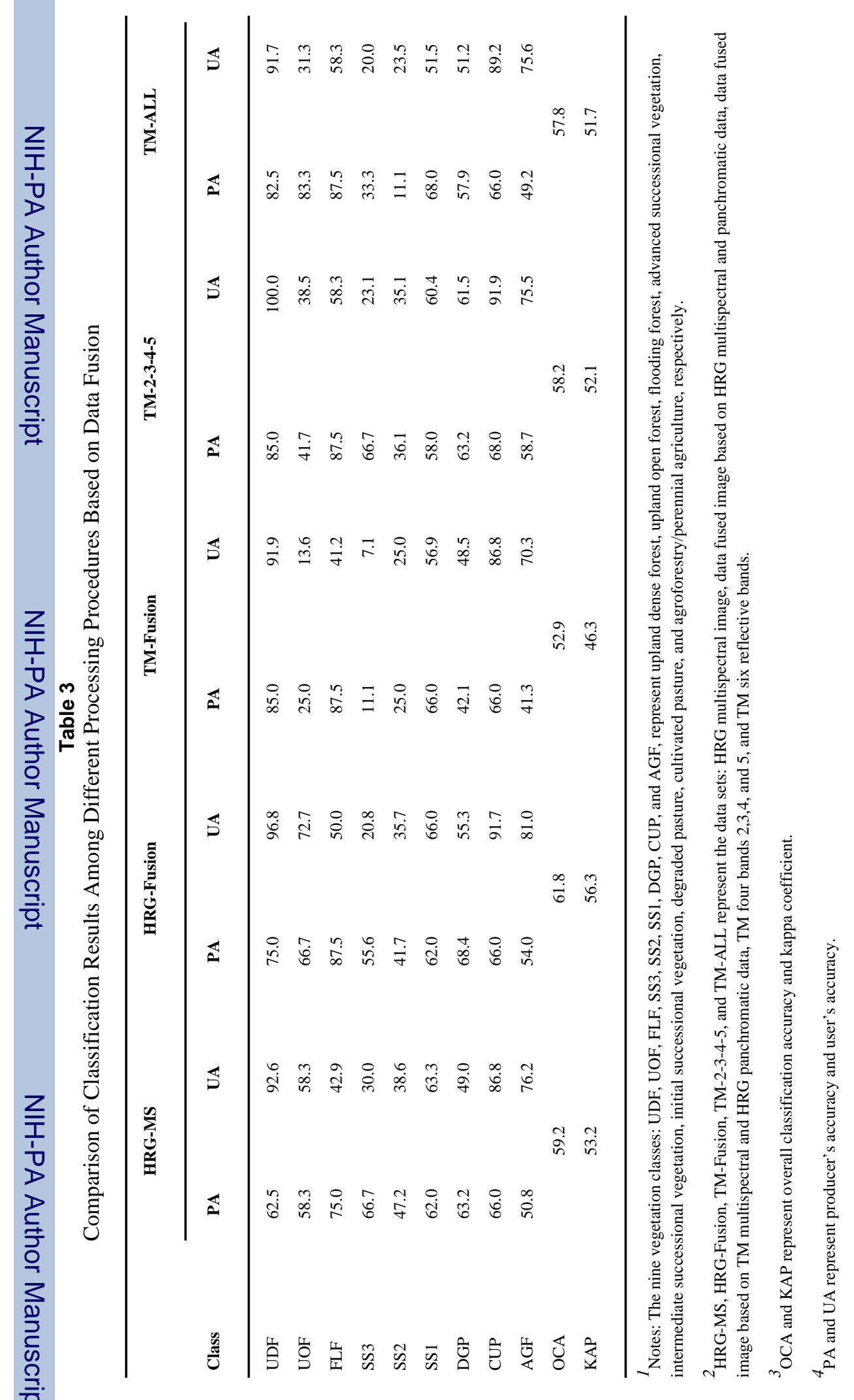

Photogramm Eng Remote Sensing. Author manuscript; available in PMC 2009 September 28. 


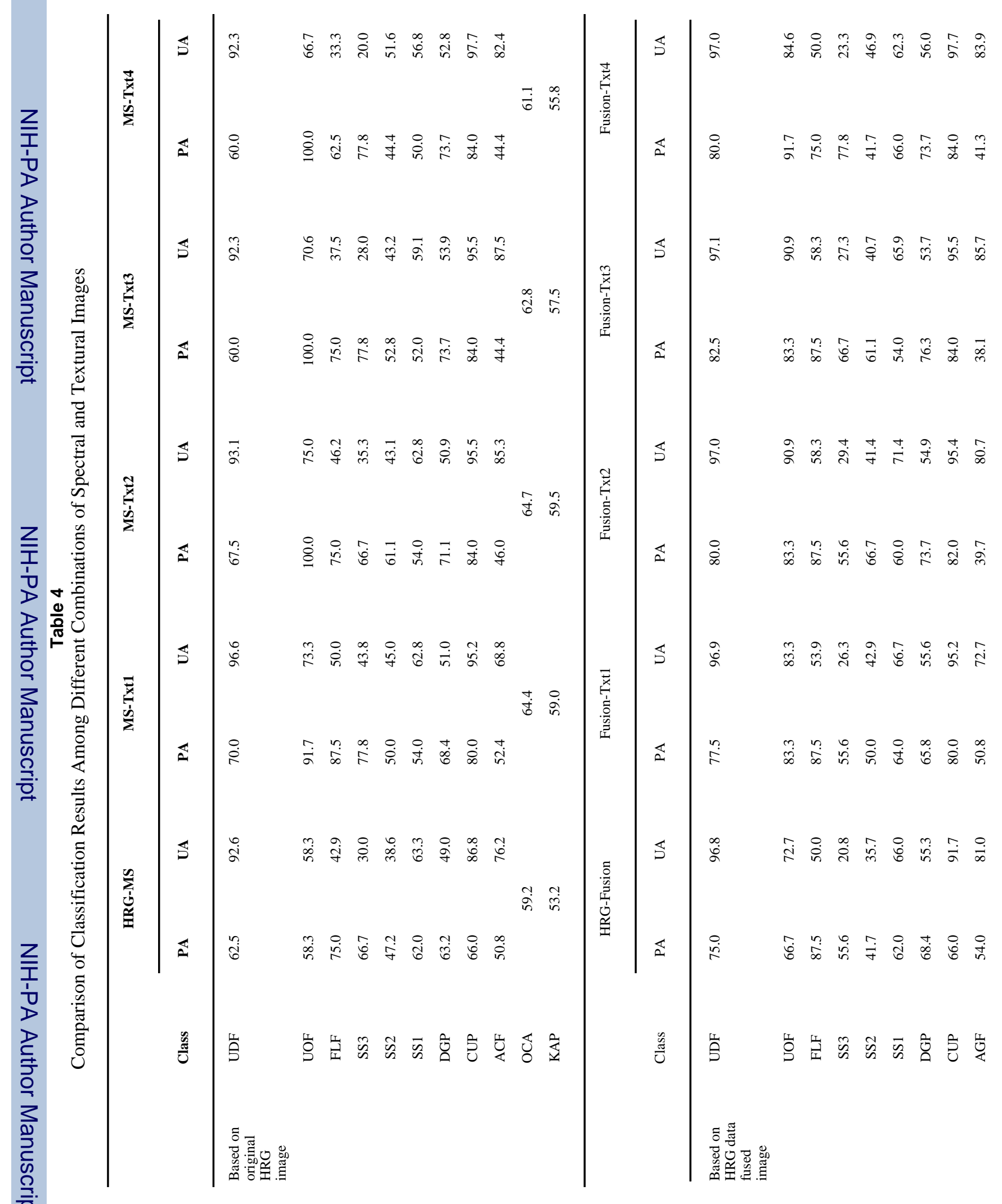




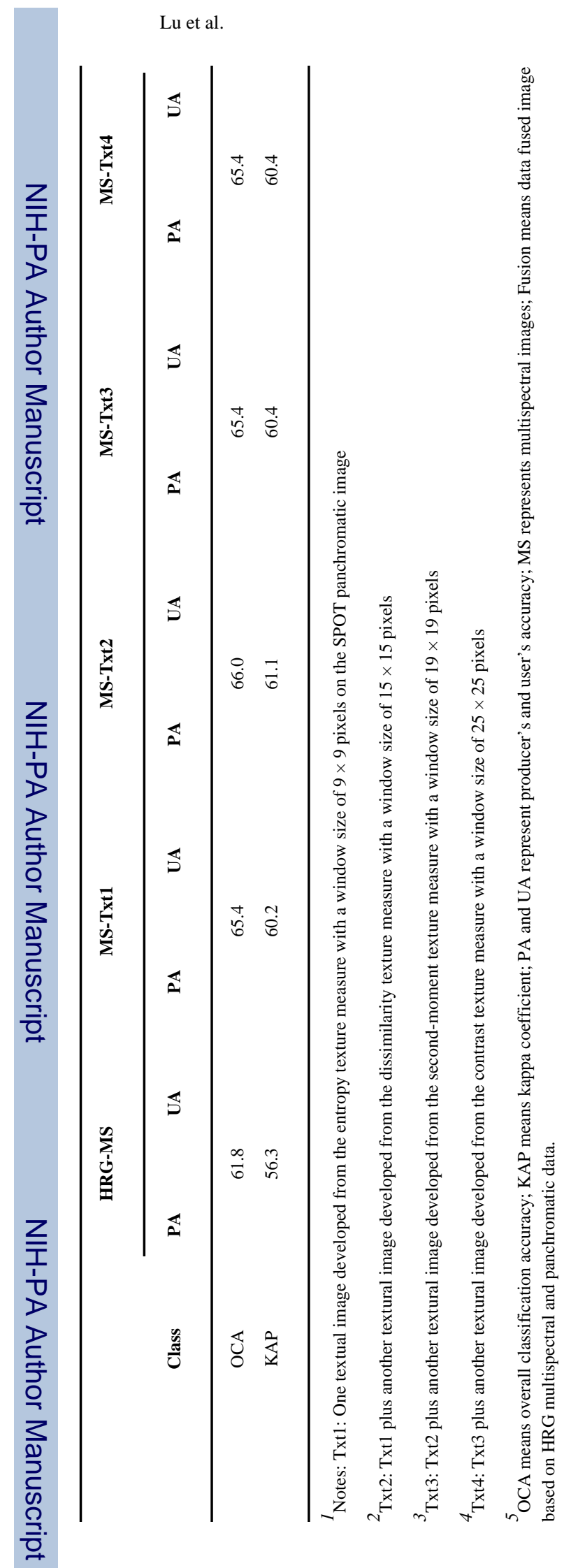

Photogramm Eng Remote Sensing. Author manuscript; available in PMC 2009 September 28. 